\title{
SUMMARY OF SCAN SITE 9
}

\author{
D. A. Johnson, S. M. Smith and G. Shor \\ Scripps Institution of Oceanography, La Jolla, California
}

\section{SURVEY AREA}

\section{General Information}

The survey area is bounded by latitudes $19^{\circ} 40^{\prime} \mathrm{N}$ and $20^{\circ} 11^{\prime} \mathrm{N}$, and longitudes $139^{\circ} 46^{\prime} \mathrm{W}$ and $140^{\circ} 27^{\prime} \mathrm{W}$; the extent of the area is 30 by 40 miles. The survey of this site was made from the Argo between April 1719,1969 . Weather conditions at time of survey (18 April, 0600) were: ENE winds of 32 knots, very rough seas (ENE) with swells of 10 to 12 feet, and an overcast sky. Barometric pressure was 30.05 ; and, sea and air temperatures were $74^{\circ} \mathrm{F}$ and $73^{\circ} \mathrm{F}$, respectively. The observed drift was variable, most likely a set to west of one knot, which probably reflects the difficulty in keeping constant heading in heavy wind and seas.

\section{Bathymetry}

The regional depth of the survey area is 5030 to 5304 meters. The area is characterized by a series of abyssal hills, generally 73 to 146 meters high, with several hills reaching heights of 366 meters. Considerable fine-scale relief is indicated by multiple echoes. Survey lines are not spaced closely enough to determine elongation of individual hills, but regional North-South topographic lineations are evident in comparing E-W profiles with $\mathrm{N}-\mathrm{S}$ profiles. A special feature of the survey area is a prominent abyssal hill or ridge with thick and broad accumulations of sediment against the north and south slopes (profile HI).

\section{Structure and Magnetics}

Relief of the deepest reflector is generally conformable with the overlying sea floor, except near the proposed site where sediment thickness is unusually high. The $3.5 \mathrm{kHz}$ echo sounder and airgun records indicate a uniform ( 0.02 to 0.06 second) accumulation of transparent sediment over most of survey area. No noticeable "ponding" effects were detected, except at the proposed drilling site where 0.20 second of sediment had accumulated.

Magnetic anomalies are lineated in a north-northwesterly direction. The amplitude of surface anomalies approximates $100 \gamma$ in a width of 30 miles.

\section{DESCRIPTION OF SITE 9}

This site is located at latitude $19^{\circ} 48.0^{\prime} \mathrm{N}$, longitude $139^{\circ} 52.6^{\prime} \mathrm{W}$ in a water depth of 5055 meters. Site 9 is positioned on the north flank of an abyssal hill or ridge, elongated in an E-W direction. A relatively thick ( 0.20 second) accumulation of sediment is present (see profile HI). Minor reflectors occur between 0.04 to 0.08 second below the sea floor. Strong reflectors occur at 0.12 and 0.20 seconds.

\section{NATURE OF SITE}

\section{SCAN-9a-P}

Core length: 1 meter. This core contains mixed reddishbrown to tan clay, with no indication of fossils.

\section{SCAN-9b-P}

Core length: 10.1 meters. This core sampled a dark brown nonfossiliferous clay.

The camera lowering at Site 9 detected abundant manganese nodules (to 10 centimeters in diameter) covering over 25 per cent of the sea floor. There was no indication of benthonic organisms or bottom currents. No measurement of heat flow was taken at this site. 


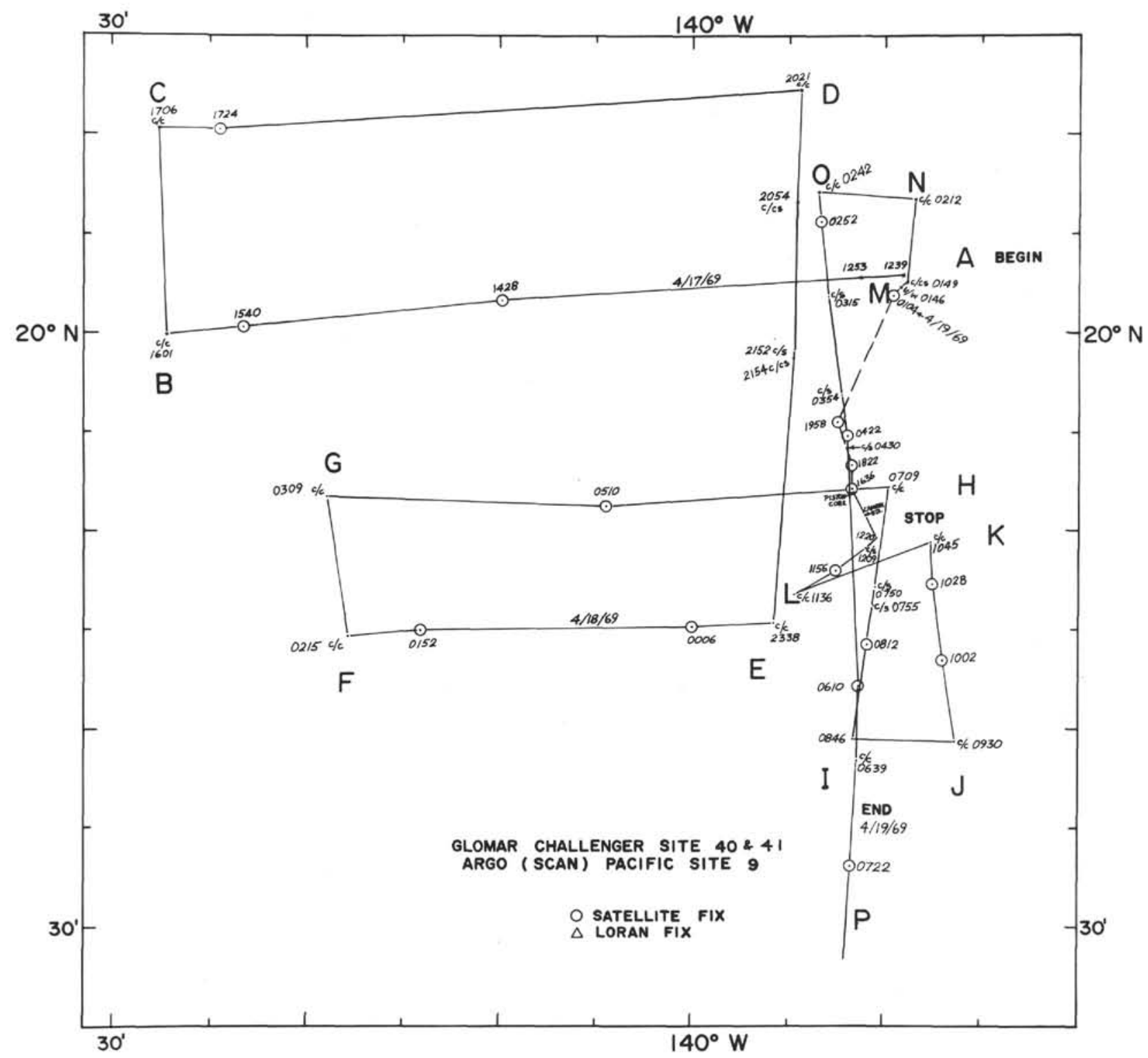



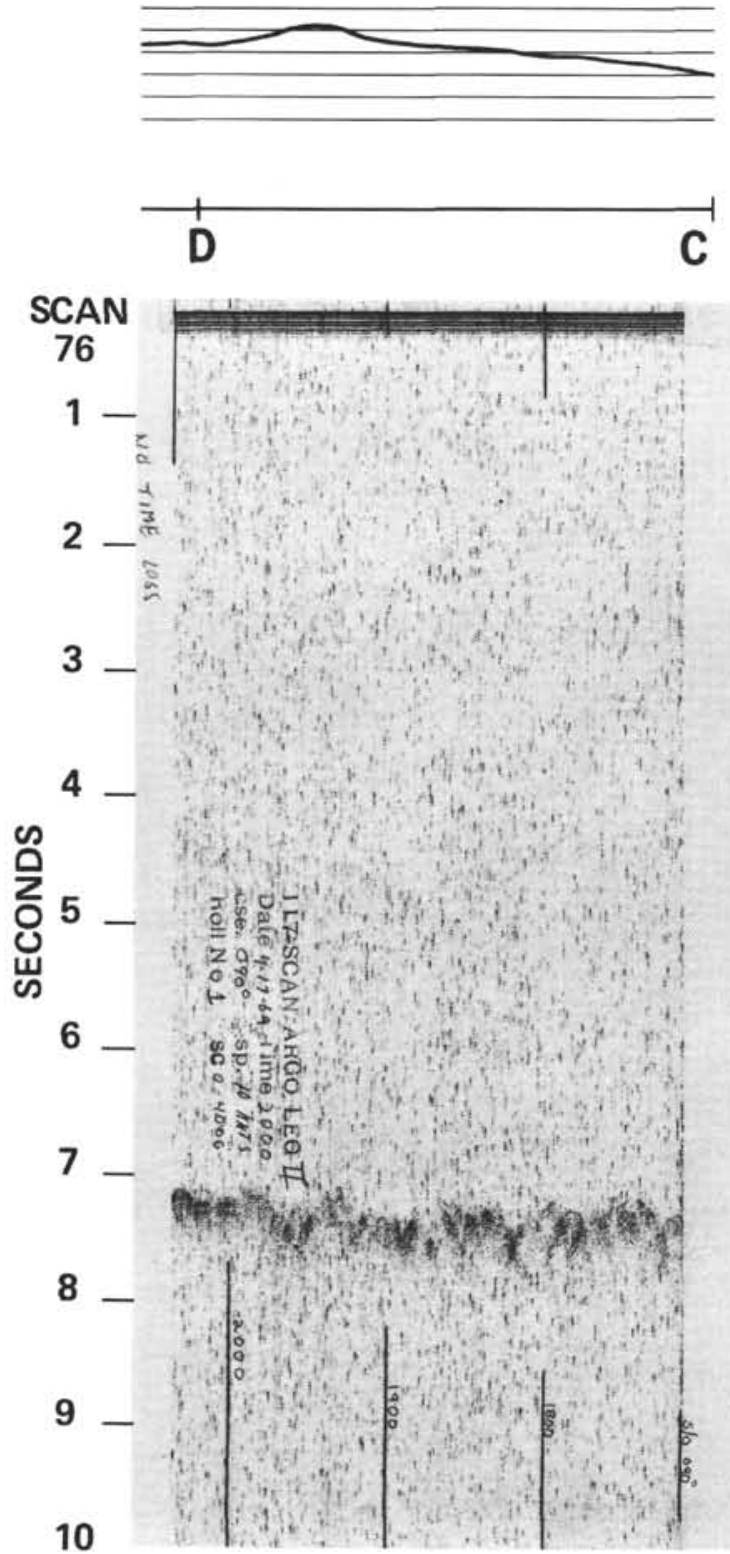
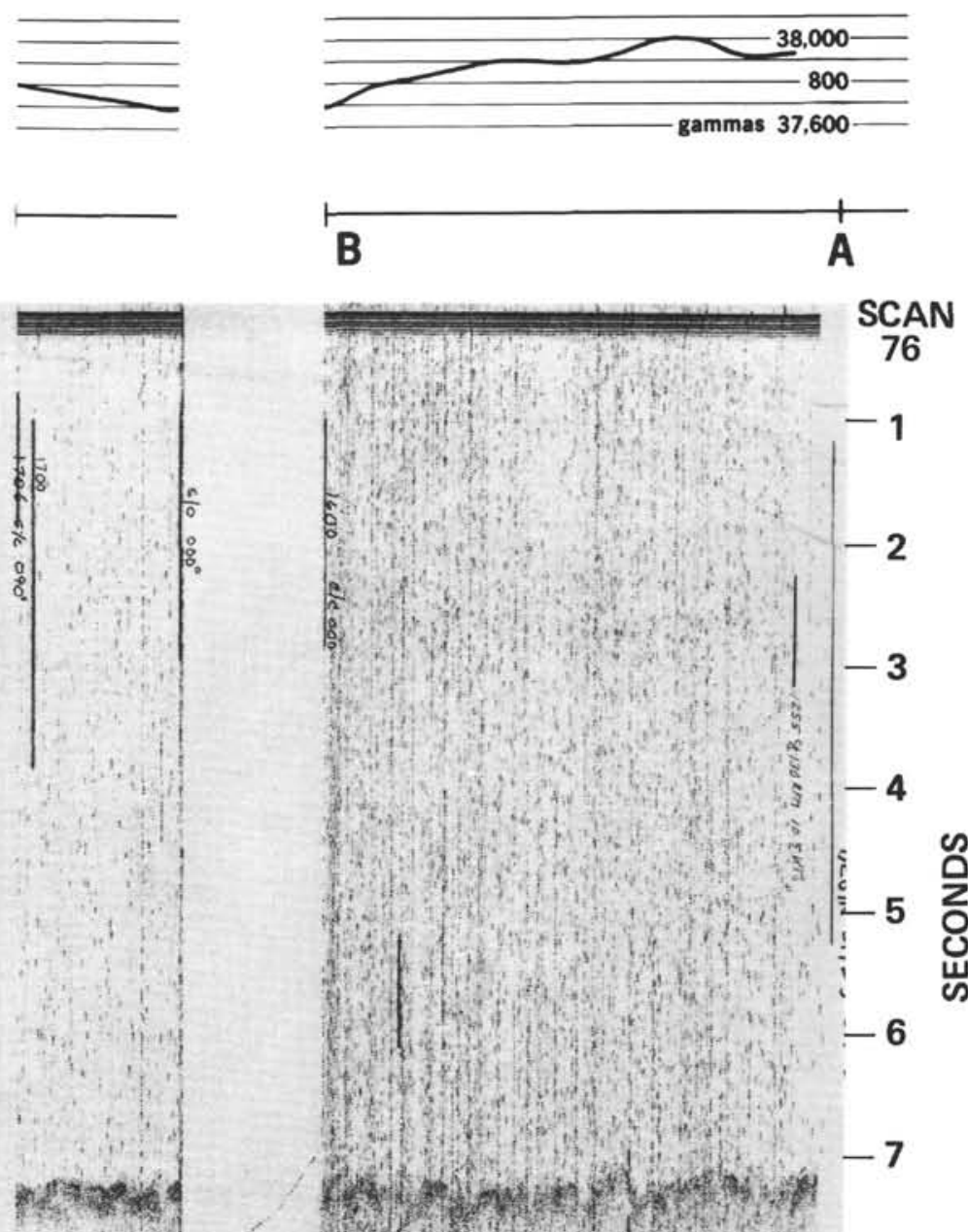

$-6$
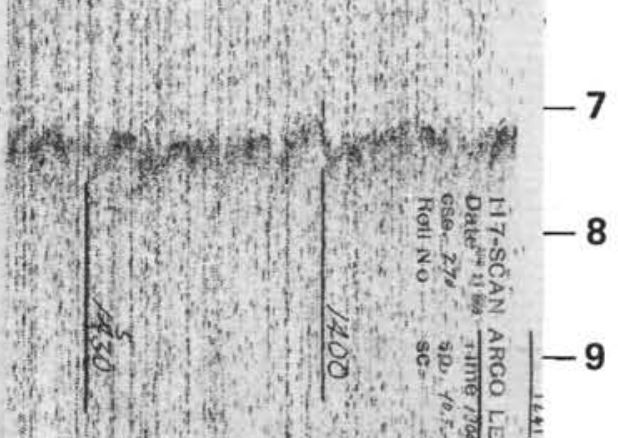

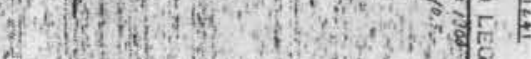

SCAN Survey, Site 9, Tracks A, B, C and D. 


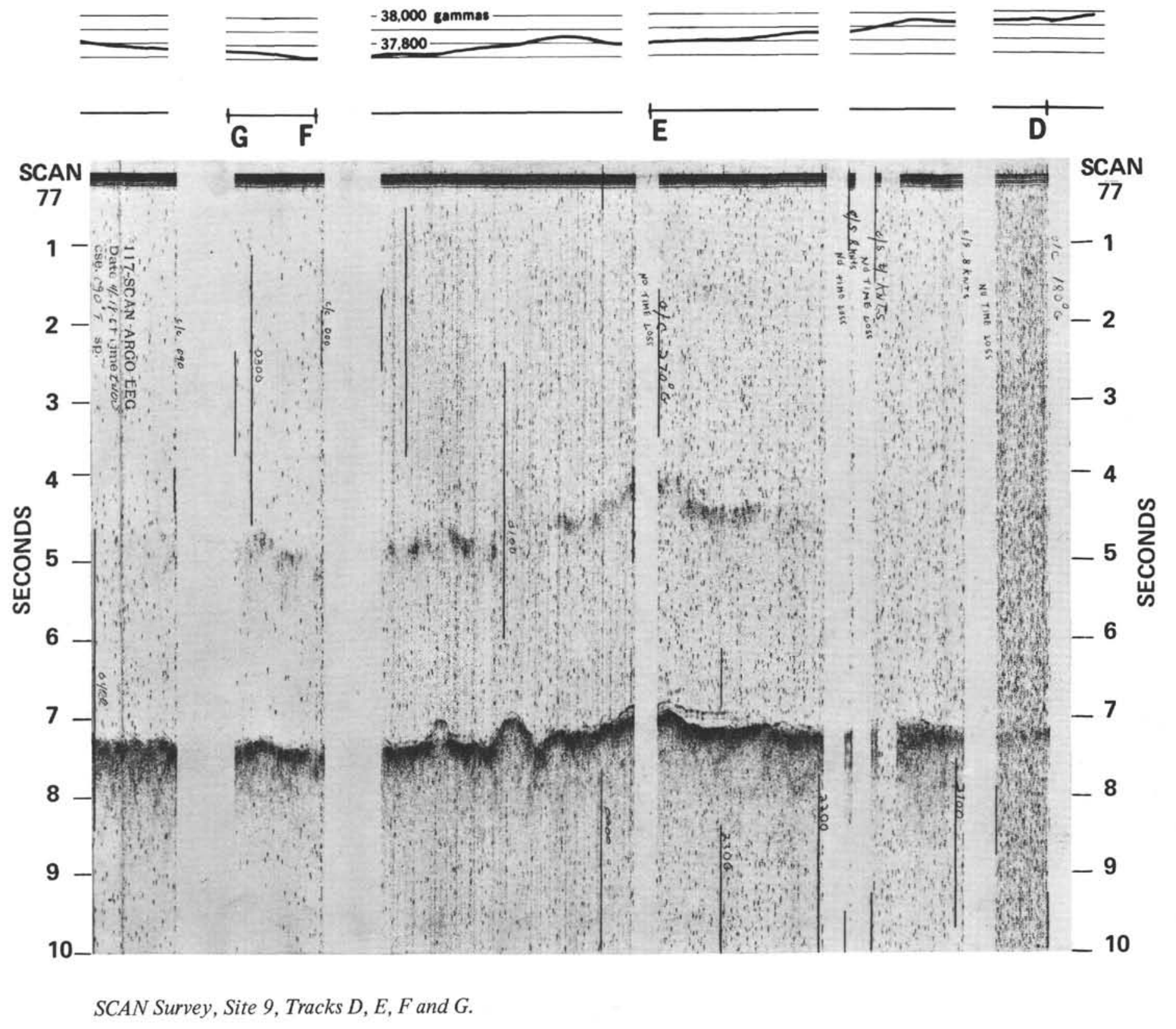



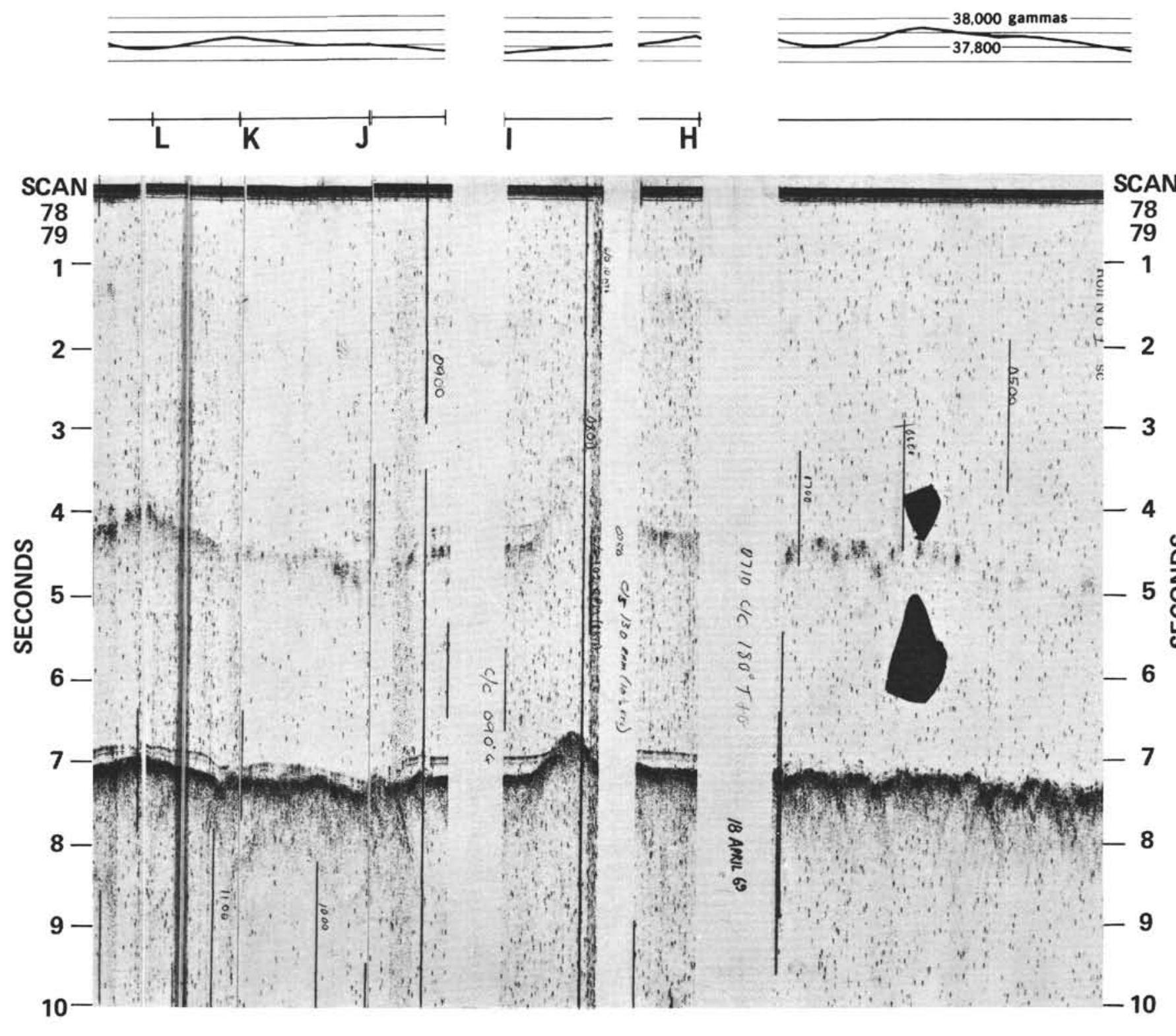

78

79

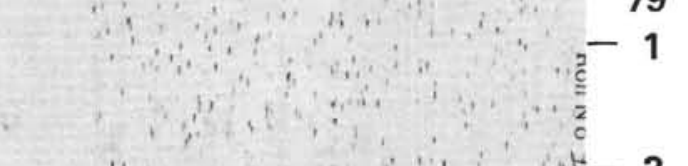

SCAN Survey, Site 9, Tracks $H, I, J, K$ and $L$. 

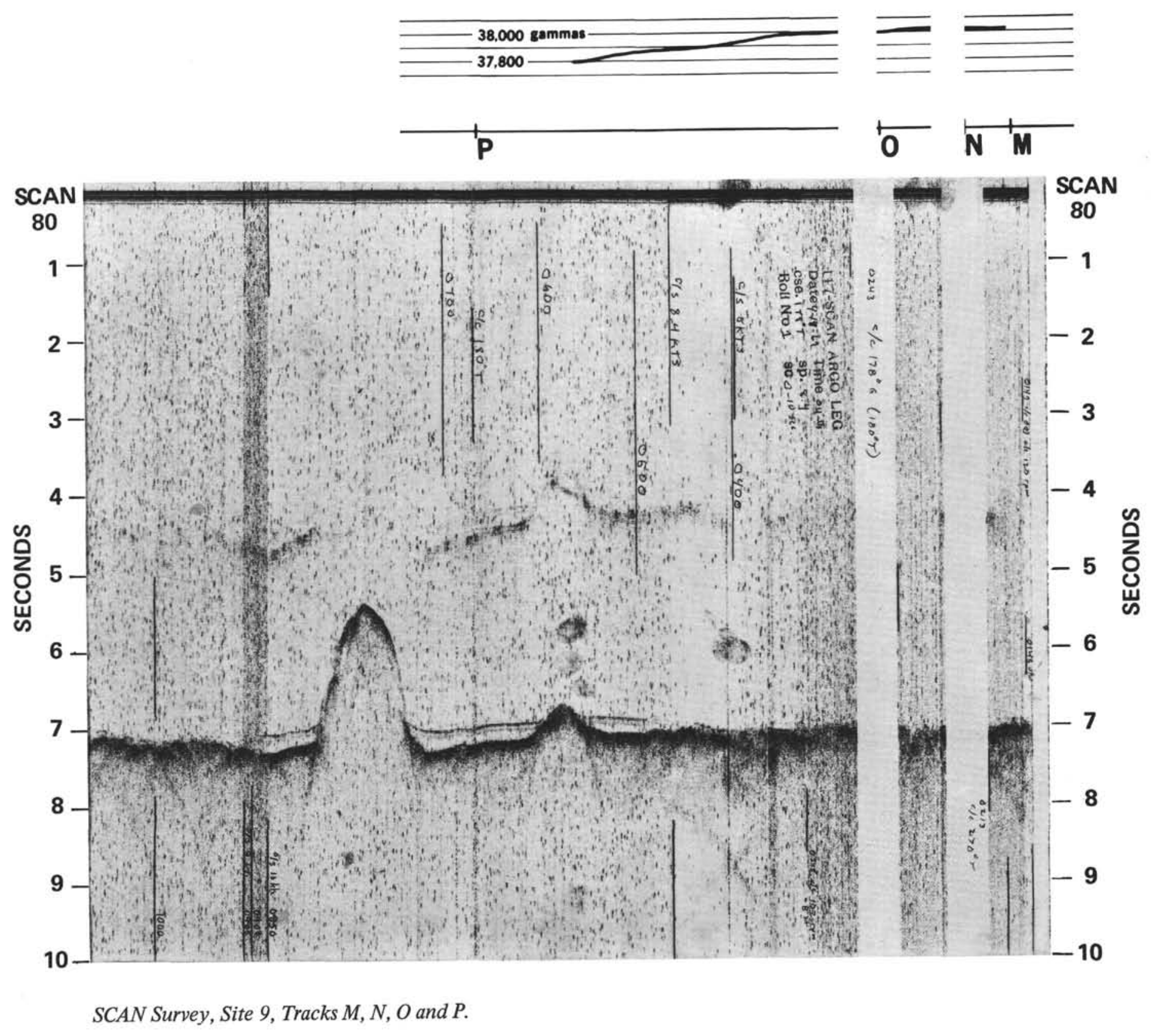


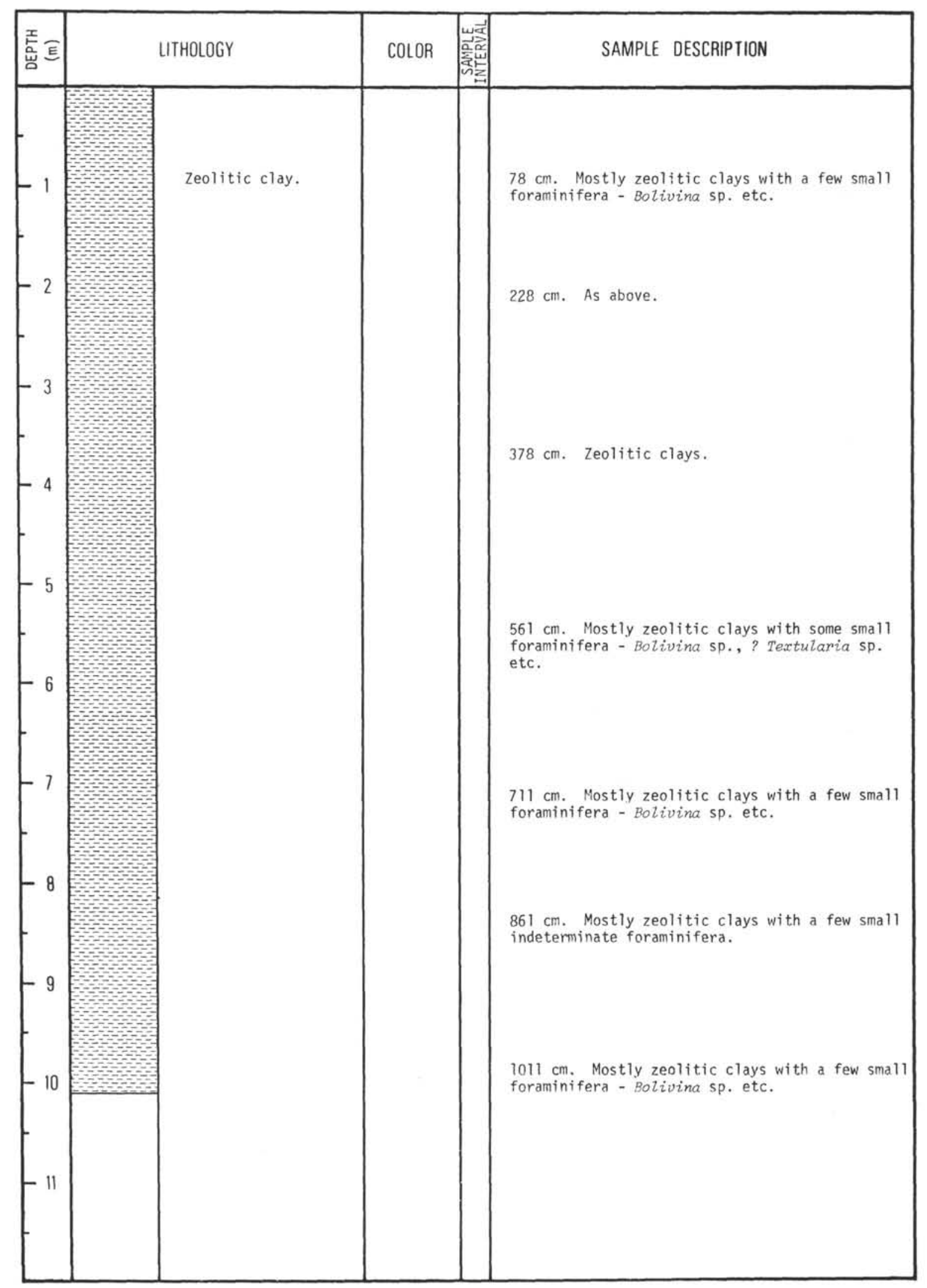

Summary of Piston Core 9. 